\title{
Smell Organisation: Bodies and Corporeal Porosity in Office Work
}

\author{
Dr. Kathleen Riach, \\ Monash University, Melbourne, Australia \\ Prof. Samantha Warren \\ Essex Business School, University of Essex, UK
}

\begin{abstract}
This paper contributes to a sensory equilibrium in studies of workplace life through a qualitative study of everyday smells in UK offices. Drawing on Csordas' (2008) phenomenology of intercorporeality, we develop the concept of corporeal porosity as a way of articulating the negotiation of bodily integrity in organisational experience. We explore the olfactory dimensions of workplace life through smell-orientated interview and diary-based methods and our findings highlight the interdependence of shared, personal, local, and cultural elementals when experiencing smell in office-based work. Our analysis highlights three elements of bodily integrity: 'cultural permeability'; 'locating smell in-between'; and 'sensual signifiers'. This suggests that whilst the senses are part of the ephemeral, affective 'glue' that floats between and around working bodies, they also foreground the constantly active character of relationality in organisational life as an entanglement of embodied traces and fragments - corporeal seeping and secretion that has hitherto taken a backseat in organisational studies of the body at work.
\end{abstract}

Keywords: Body, Bodily Integrity, Corporeal Porosity, Csordas, Embodiment, Intercorporeality, Office Work, Qualitative Research, Sensory Methods, Smell 


\section{Introduction}

Recent research acknowledges organisational experience as seen, touched, felt or heard (Cunliffe and Coupland, 2012; Hindmarsh and Pilnick, 2007; Hockey, 2009). In this article, we focus on smell as a phenomenon par excellence for acknowledging that embodied lived experiences of work in organisations are not only felt and known through the body, but play a fundamental role in the ontological imperative of embodied subjectivity - understood here as 'bodily integrity' (Shildrick, 2010; Weiss, 1999). We argue that the porosity of the body must be considered when exploring how conditions of bodily possibility are experienced and transformed - a thesis empirically highlighted in the incorporation and morphology of the sensual world. As a small number of studies have already recognised (e.g. Corbett, 2006; Hockey, 2009; Martin, 2002), the ephemerality of smell presents opportunities to explore the corporeal dimensions of embodiment as not only situated on the body but continually moving in and through a permeable body (Ingold, 2011). As such, 'the boundaries of a living body are open and indeterminate: more like membranes than barriers [...] so that it is very difficult to discern, at any moment, precisely where this living body begins and where it ends' (Abram, 1996: 46-47). This position provides an opportunity to extend current focus on the dialectical relations of discourse and flesh through forefronting a particularity of movement into the body - important but underexplored bodily vectors in embodied debates. To mobilise this perspective, we situate our study within Csordas' treatise on intercorporeality in order to empirically explore the experience of smell at work for 14 white-collar office employees in the UK.

As the inaugural issue of the journal Senses and Society (2006: 5) argues, the senses are 'fundamental to our experience of reality, and the sociality of sensation cries out for more concerted attention'. Smell is an inherent part of the broader inter-sensory life: a life that is 
invariably experienced through synesthetic social relations, and not 'sliced up along the lines of the sensory pathways by which we enter into it' (Ingold, 2011: 136). However, it can be argued that smell has unique characteristics which merit its study as a phenomenon in its own right, and as a useful 'entry point' into the sensorium. Unlike other sensorial apparatus which transduce via electrical impulses, smell has a direct neural pathway to the limbic system, which is one of the oldest parts of the brain and also responsible for memory and emotion (Shepherd, 2005). As Gell (1977) suggests, smell is also unique in its 'semiological ambiguity'. On the one hand it cannot be understood purely as a sign-system due to its physiological characteristics, but on the other, it cannot be understood as solely biological since it is intertwined with experience, symbolism and meaning. Thus smell is not just a 'sensation', but instead is one element of an experiential system that summons us to the world so that both the world and our selves are constituted through that experience. While the olfactory process occurs within milliseconds, its immediate and intimate connection to memories or emotions has contributed to its reputation as a potent sense (Verbeek and van Campen, 2013). The opportunity to influence stakeholder behaviours via smell has not been lost on marketers, commerce or institutions (Davies et al., 2003; Lindstrom, 2010; Morrin, 2010; Shepherd, 2010; Williams, 2000). These reports, so far confined largely to media and/ or popular texts, suggest the need for a sustained debate on the experience of smell in organisational settings that considers the social, cultural and bodily processes at play - or at stake - in these endeavours. How does smell engagement as a 'somatic mode of attention', or deep attachment (Csordas, 1993) constitute or reproduce relations between workers, coworkers and their surroundings? In what ways is smelling situated in, or abstracted from, the propinquities of organisational life? And to what extent does smell provide a means of understanding the often unspoken dimensions of porous bodies working alongside other porous bodies? 
To a large extent, situating bodies as active meaning makers, socially situated subjects and biologically material entities remains a problematic at the heart of exploring the lived experience of work in organisations. Recent accounts of organisational bodies have departed from traditional interpretations of a passive vessel towards an appreciation of its active role in the constitution of workplace relations (Cunliffe and Coupland, 2012; Dale, 2001; Driver, 2008). An important aspect of research examining embodied sociality has been to explore how the lived experience of a changing body is negotiated alongside meanings or discourses surrounding the professional body that follow rationalist archetypes ascribed in professional ideologies of work (Haynes, 2008). However, while the pervasiveness of various technologies to control the self has been previously accounted for through a focus on discourse as written on the body, this rarely extends to the sustained utility of phenomenological 'fleshiness' and a consideration of the theoretical and corporeal porosity of bodies. Specifically, empirical explorations that focus on corporeality often fall into what Dale (2001: 71) calls an " "anatomising urge" [...] (trying) to render the body visible, inside and out'. However, their analysis does suggest the importance of teasing out how the interplay between culture and the body is experienced at the level of everyday action and negotiation in particular organisational settings. This encapsulates not only the communal processes involved in being and becoming as bodily, but how this is also constituted through the active negotiation of what goes in and out of the body - something of equal ontological consideration when thinking about embodied lives. To explore the complexity of these experiences, and in so doing understand the body's potential to create, assert and shape selfhood, it is imperative to recognise the utility of the senses in highlighting the negotiation of such permeability. 
Our article extends current studies of bodies at work in four ways. Theoretically, we draw on a phenomenological understanding of bodily integrity as a means of extending current understandings of organisational embodiment. In particular, we develop Csordas' (2008) phenomenological stance on intercorporeality to highlight how conditions of bodily possibility rely on the ontological imperatives of bodily integrity. Conceptually, we mobilise this position through developing the concept of corporeal porosity to foreground the social and material permeability of embodiment. This affords one way of exploring sensory experiences that have been hitherto regarded as first and foremost individually situated. Empirically, we focus on smell at work rather than the more culturally dominant senses (sight and hearing) in order to move towards what Classen et al. (1994: 10) term a 'sensory equilibrium' in studies of work. While recognising the limitation of extracting smell from the multisensory context in which it is experienced, we believe focusing exclusively on smell prevents it from being marginalised by other senses that are either perceived as more accessible and communicable between individuals, or easier to articulate due to the vocabularies that surround them. We also develop new methodological ways of researching the senses in order to focus on the experiences of smell for those engaged in office-based work. Offices have been overlooked by sensory studies in favour of studying manual or physical-based occupations where strong odours and smells are more immediate (Hockey and Allen-Collinson, 2009). Yet, as we will demonstrate, offices constitute a particular type of organisational smellscape where 'smells may be spatially ordered or place related' (Porteous, 1985: 359).

\section{Smelling Bodies at Work}

Academic anosmia, understood as the absence of smell, has been attributed to the traditionally occularcentric character of science and especially to the privileging of sight in 
business and management studies (Corbett, 2006; Kavanagh, 2004). This has the effect of relegating other senses to a position of lesser importance when exploring the sensual 'micropolitics of bodily interaction' (Wolkowitz, 2006: 161). Studies that do address smell are concentrated in areas where the work is viewed as explicitly 'bodily', including sex work (Wolkowitz, 2006: 126) care work (Jervis, 2001; Martin, 2002), and food service industries (Fine, 1996; Lyon and Back, 2012) and mainly emphasise bodily regulation and conduct. Other accounts focus on 'using' smell in the course of work, such as the historic importance of smell aiding medical diagnoses (Palmer, 1993) or for communicating aesthetic discourses around culinary production and consumption (Fine, 1996). The potential for 'organisational researchers to take the sense of smell seriously in order to explore the invisible, sensual aspects of organisational behaviour' (Corbett, 2006: 230) has become more theoretically feasible through researchers taking a broadly phenomenological approach. This suggests that 'before thinking and representing the world, we embody it' (Flores-Pereira et al., 2008: 1008). We are aware of phenomena - that is 'things' as they appear to us - 'insofar as we are orientated toward and aware of them as things with meaning-for-us, and in so being become aware of ourselves in such directed relations' (Holt and Sandberg, 2011: 218). Indeed, in discussing hearing and vision, Ingold (2011: 137) goes so far as to say it is only the recognition of sensory experience as 'a sense' that allows us to make meaning at all. Similarly, Gabor's (2013:15) study of musicians suggests that taken for granted skills are not only inculcated into the body, but are created through physical action and meaning, giving us a sense of how and what the world is. Highlighting that 'issues of subjectivity feel real' (Tomkins and Eatough, 2013: 260 emphasis in original) has enabled empirical analyses to foreground the body as sensually active and the integral role of senses in constituting the lived experience of work through a phenomenological lens. For example, Hockey's (2009) study of life as an infantryman in the British Army as experienced through the senses shows 
how the stench of sweat and hard, outdoor, manual work signals a 'real soldier', and how the acrid smell of explosives and burnt flesh is etched on the memories of serving personnel. Elsewhere, Cunliffe and Coupland (2012: 68) have recognised the embodied nature of sensemaking narratives. These accounts invite us to explore the materiality of the body as being more than a physical or symbolic indicator while at the same time avoiding the 'disembedded and disembodied' (Cunliffe and Coupland, 2012: 68) effect of regarding the body as only a discursive project.

Locating the body as a site of social creation also helps us to consider sensory experience itself as a permeable and shared phenomenon, in which 'we make our lives sensible in lived responsive and embodied moments as we struggle to make meaning with others' (Cunliffe and Coupland, 2012: 67). Despite this communal potential, Hindmarsh and Pilnick (2007) argue that subjectivity and corporeality are still regarded as prima facie individual constructs, particularly within a workplace context. The idea that embodied experience resides at the level of discrete individuals is an intuitive one, in western culture at least. However, it poses theoretical problems when we consider ephemeral phenomena such as smell, which cannot be entirely located at the site of objects nor completely within subjects. In other words, assuming that as bodies we are separate from the world (including from one another) underplays the significance of our interpersonal lived experience. Subsequent empirical accounts have sought to undermine this individualist ontology, such as Hockey and AllenCollinson's (2009: 223) description of how workers 'skillfully coordinate their bodies in time with co-workers or machinery', Hindmarsh and Pilnick's (2007) account of the assemblages of movements that occur between bodies that constitute anaesthetic teamwork, and Ingold's (2011: 121) discussion of hunters in southern Africa for whom 'the whole environment is 
riddled with [...] scent threads binding its human and non-human inhabitants into an intricate mesh...'

The above phenomenologically-inspired accounts of embodiment highlight the consequences of thinking about co-constituted bodies in terms of subsequent behaviours or visible manifestations. This appears to be a consequence of Merleau-Ponty's influence where the manifestation of the visible forms a key means of sensibility. However, we argue that embodiment must also take into account the corporeal significance found within fragments of body experiences that resist visible manifestation but are nonetheless involved in this process of mediation, reciprocity and exchange. This is the focus of Merleau-Ponty's later work (1968) where he introduces a phenomenology of flesh. Flesh is not simply the surface of the body or matter in itself, but is characterised by the potential reversibility of sensual experiences (such as touching/touched). Merleau-Ponty (1968: 138) uses the metaphor of a 'coiling over' as a means of articulating what he sees as the 'reciprocal insertion and intertwining of one in the other' that constitutes our conditions for (embodied) subjectivity. Of importance here is the insertion and intertwining as always bodily and points to a depth of corporeal porosity that produces an inevitable bond we have between selves. There is on the one hand a reliance on corporeal porosity for our subjectivity, and yet on the other hand, in order to become a subject we need to conceive of ourselves as bounded beings. Thus the question becomes how we maintain bodily integrity when our very constitution relies on porosity. While studies have explored these simultaneous negotiations of corporeal coherence and synchronicity within medicalised experiences (Shildrick, 2010; Weiss, 1999), within the workplace context there is an embedded level of complexity, since organisational-level dynamics may have a pervasive influence on how we navigate our lived experience of work. 


\section{Smell and Intercorporeal Inhalation}

Sensual anthropology offers possibilities for exploring the conditions and consequences of corporeal porosity as a basis of embodiment, since it notes both the socio-cultural import and material significance of a wide range of sensual experiences (Abram, 1996; Classen, 1997; Classen et al., 1994; Howes, 2010; Low, 2005; Ong, 1969; Wade, 2009). Waskul et al. (2009) suggest that literatures on smell focus on two interconnected dimensions. The first focuses on sensuous rituals that relate to the patterns formed through individual or collective biographical experiences, and the responses we have as a result of being 'socialised' into smell (Curtis, 2008; Low, 2005; Radcliffe-Brown, 1964; Synnott, 1991). The second branch of inquiry focuses on the sense-making rituals where smell or aroma is a means of creating, replicating or reproducing social relations (Classen et al., 1994; Corbin, 1986; Gell, 1977; Mason and Davies, 2009; Rasmussen, 1999). Importantly for our purposes here, within both streams of literature, there is recognition that subjectivity is situated between relations and the 'surfaces' or boundaries of people and things only appear to separate one kind of materiality from another. We should, therefore, take care not 'to slip from the physical separation of gaseous medium from solid substance to the metaphysical separation of mind and matter' (Ingold, 2011: 22). In relation to smell, bodies excrete substances with more or less detectable odours, and so we routinely inhale and ingest particles of every-body and every-thing we come into proximity with. However, at the same time, smell captures this movement of fragments that are simultaneously (i) in ourselves but (ii) not fully of ourselves, and yet (iii) make our selves.

Odour is one site where bodily integrity may be glimpsed, highlighting how we affect one another in daily life as part of 'those resonances that circulate about, between and sometimes stick to bodies and worlds...visceral forces beneath, alongside, or generally other than 
conscious knowing...that can serve to drive us toward movement, toward thought and extension...' (Seigworth and Gregg, 2010: 1, emphasis in original). This is the focus of Csordas' $(1999,2008)$ thesis, which suggests that we intuit intention through subtle, nuanced and instantaneous practices at a barely conscious level, if we are even aware of them at all. Importantly for Csordas, this intuition happens at the level of bodily engagement, manifest in shared bodily exchanges in specific cultural contexts and what he calls the 'filaments of intentionality that crisscross between and among us humans' (Csordas, 2008: 118). Importantly, it is in these patterns that culture is negotiated and manifested. Bodies are not just receivers of cultural signals carried along in the air by particles of smell, but the originator of culture through a 'somatic mode of attention' (Csordas, 1993), highlighting embodiment as the locus for culture and self.

Flores-Pereira et al., (2008) use this idea to situate organisational culture as an embodied practice through exploring after work drinking rituals. In this account they note: 'the ritualised body is not a modus operandi for the work of culture: what the body performs during the ritual are ends in themselves' (Flores-Pereira et al., 2008: 1014-15). This independence offers an alternative way of exploring the collectively-recognised-but-highlyindividualised experience of work and labour. As such, developing corporeal porosity as first and foremost intercorporeal allows recognition that any sensual practice, including smell at work, involves recognising the other as physically separate yet simultaneously and inescapably connected to us. We understand this as bodies and other elementals of the social being corporally 'inhaled' into us by ontological necessity. Indeed, the concept of inhalation captures this experience as grounded in the body. Just as we need to breathe as a biological necessity, we must inhale in order to sustain conditions of subjectivity. Inhaling also involves a continual exchange and enmeshment of experience that challenges and confuses ideas of 
interiority and exteriority. The social and historical intimately weave within and across bodies to the extent that 'the body is both active and acted upon: a locus of action and target of power' (Crossley, 1996: 104). Csordas' work therefore helps us remember that 'to smell' is necessary at both a material and ontological level. This hybridity suggests a simultaneous process whereby smell becomes one means through which employees negotiate bodily integrity at work and experience the conditions of bodily possibility within this arena. It is to the empirical mobilisation of these ideas that we now turn, introducing the methods of our study, before presenting our data analysis.

\section{Methodology}

The empirical section of this paper draws on data from a wider multi-method project investigating smell and organisation in UK workplaces, and which used a variety of sensoryled methods to generate data. All participants were based in the South of England, UK, ranging from 27 to 59 years old, and were employed full-time in fixed office locations. Specifically, the findings we present below are derived from analysis of interview transcripts and 'smell diary' entries from 14 UK-born participants (five men, nine women and herein referred to by pseudonyms) who responded to a call for employees who worked in 'traditional white collar office spaces'. The exploratory methodology has been discussed at length elsewhere (see Warren and Riach 2014), but to précis here, the data collection process was deliberately designed to give priority to smell, or as Drobnick (2006: 3) states 'invite immersion into an evanescent olfactocentric realm'. In a similar way that one might choose a critical case study to best illuminate a specific topic, we developed techniques that encouraged participants to particularly focus on odours, aroma and smelling within their workplace sensory landscapes. Beginning from methodological accounts in sensory studies (Hockey, 2009; Mason and Davies, 2009; Pink, 2009), our research design evolved through 
experimenting using techniques employed in scent marketing research (e.g. Morrin, 2010) and psychological experiments involving smell (e.g. Herz, 2003). After piloting a variety of techniques using postgraduate student volunteers, we finalised a three stage design: (1) videotaped 'smell interviews' (average length 62 minutes) which included initial dialogue about participants' experience of smell at work followed by a more focused discussion using mouliettes (paper strips) impregnated with 'office smells' such as coffee, sweat and 'wooden desk'; (2) audio smell diaries, recorded over a period of one working week whenever the participant encountered a 'smell episode' they wished to note (average of nine entries per participant); (3) a second round of face to face interviews (digitally recorded, average 55 minutes) where individuals further discussed their diary entries alongside pictorial representations of their workspaces.

The process of analysis was iterative and led by Waskul and Vannini's (2008: 54) notion of 'somatic work' which focuses on the 'activities individuals [use to] produce, extinguish, manage, reproduce, negotiate, interrupt, and/or communicate somatic sensations in order to make them congruent with personal, interpersonal, and/or cultural notions of moral, aesthetic, or and/or logical desirability'. Technically, this involved coding over 600 pages of A4 typed text transcribed from the audio data using NVivo 9. The logocentric reduction of the sense experiences that occurred in both the research interactions and the participants' everyday experiences of their work spaces is recognised as a limitation. However, analysis was careful to focus on the interplay between sense experience (for example, when smelling the mouliettes) and its articulation, advocating that 'what is important is not the felt sense as distinct from the word so much as the interplay between felt sense and word, for we can learn a great deal from how comfortable or otherwise that interplay is'. (Tomkins and Eatough, 2013: 268). Grounded codes identified from the initial analysis were combined with a priori 
concepts drawn from key debates in anthropological and ethnographic literatures dealing with behaviour and actions associated with smell, such as Classen et al.'s (1994) classification of olfactory dimensions and Pink's (2009: 125) account of localised sensory categories.

While our study is empirically limited to our fourteen participants' specific bio-social experiences in a particular space and time, we nonetheless contend that our findings might be relevant to the experiences of other office-based workers given that our research focuses on the more mundane and everyday smellscapes - that is, the spatial ordering and material location of white collar work, rather than the manual or physical occupations and jobs often aligned with stronger odours (Hockey and Allen-Collinson, 2009). Furthermore, our sample was deliberately drawn from a range of fairly 'typical' white-collar work settings where the physical office architecture routinely brought participants into sensory proximity with coworkers and their smells. Features included purpose built or converted office buildings with centralised air control systems that regulated heating and air conditioning, and seating configurations such as fixed personal desks and open-plan or multi-occupancy offices. Thus we highlight how exploring smell as an embodied experience can inform us of how microsocial processes of being together at work are enacted between bodies-who-organise and constitute the conditions of bodily integrity.

\section{Findings: Negotiating Corporeal Porosity}

The following analysis seeks to build on the empirical mobilisation of bodily integrity through a discussion of three dimensions that focus particularly on the embodied negotiation of porosity within the everyday context of workplaces. The discussion that follows identifies three themes - cultural permeability; locating smell 'in-between'; and sensual signifiers that highlight the ways in which our participants' experiences of smell-in-the-moment, their 
personal histories, organisational contexts, and the presence of others all blended together. To highlight this fusion, each section begins with an annotated quotation explicitly identifying these different elements.

Cultural permeability: to smell or not to smell?

Cultural permeability can be understood as tension between the expectations and ascriptions of control located in organisational cultures, and the experience of smell as ephemeral, unbounded and often peripatetic. One of the key strengths of an intercorporeal focus is its potential to 'make visible' the fragments of cultures that manifest between bodies (Csordas, 1993). This was situated in ambivalent smell assertions where participants suggest that offices should not smell, while at the same time provide a number of examples of odourising practices at work:

'For me I think there's this notion that one is professional (1) and I think to be professional is not to stink, not to smell (2). And that we do everything in our power to try and eradicate kind of body odour (3), body scent through deodorants and you know - sometimes perfumes (4).' (Keiran)

Here, Keiran recognises that the ideal working body is odourless (2), and that bodily exchanges of, in this case, not-smelling are wrapped up in a cultural delineation of being 'a professional' (1). The experience of intercorporeality can be glimpsed through the effort it takes to ensure one is free from smell in a professional work context (3), and indeed requires the active labour of re-odourisation in culturally appropriate ways (4) as we explore further in this section. 
Here smell is clearly contextualised within ideas of the workplace and expectations that propagate through them. In many cases, our interviews began with participants apologising for the lack of smells in their workplaces, even though in the days running up to their first interview they had been actively trying to notice odours. The idea of non-smell is by no means value free. By having 'no smell', the workplace smellscape appeared to be held up as another feature of the traditional impersonalised bureaucracy (c.f. Weber, 1968). As such, there was initially little acknowledgement of the smells that people bring in through their presence or various day to day activities, and what people wanted or preferred to smell:

'I think most places have kind of forgotten about it, and it's like, no smell is a good smell. I think this is almost veering towards... you can't really characterise it. It's like having no real strong smell.' (Henrik)

'The office is such a sort of sterile environment it's not really occurred [to me]... it is not really that exciting, anyway. I mean, sometimes it is in terms of the work that we do, but in terms of as a space, you know, visually or smell or spatially, it's not hugely inspiring.' (Steven)

'There shouldn't be...I don't think there should be a distinct smell at work because you don't want to get distracted.' (Angela)

Here we can see the operation of culture rendering smell as an 'absent presence' that is devoid of bodies (c.f. Shilling, 1993). While participant interviews and diaries clearly showed evidence of a melée of smells in their workplaces, smell was initially noted at the beginning of the research interactions only as being 'very neutral' (Sandra). The smells actually present in the workplace were experienced as 'imposing' on this blank canvas, rather than 
constituting part of how it should smell. In aligning this neutrality with professionalism, people were thus positioned ideally as minimal indentations on this smellscape and, importantly for our purposes here, the intercorporeal bodily exchanges that were undoubtedly present were suppressed through a shared cultural recognition that work should not smell. Participants identified themselves and colleagues as responsible for minimalising smell that may detract or distract from the primary task of labour, even if the smell was not directly caused by them. Examples included getting rid of unpleasant smells made by people, such as from food being prepared, or the smell of toilets. On a personal odourising level, participants also referred to choosing a quantity and strength of perfume and aftershaves which would fit in with, or enable a return to the apparent neutrality of workplace. However, since office spaces rarely allowed for the control of air flow due to centrally controlled air conditioning and an inability to open windows or doors, this may involve using room spray (Keiran), air freshener (Olivia) or a scented candle (Sandra).

In attempting to aspire to this ideal of an odour free landscape, participants became involved in a number of active odourising routines which called into question how 'neutral' these workplace smells actually were. For example, personal odourising practices were undertaken to avoid 'bodily invasions' that would 'mark' both the organisational smellscape and particular people:

'I do wear perfume to work. And I do try and wear what I consider to be light fragrances, rather like, I've got that Elizabeth Arden one, Tea Tree, is it? It's green. It's fresh. Quite fresh...I don't like Poison, but I wouldn't wear that to work, you know, or... One of my favourites is Clinique Aromatics, and I tend to use that in the evenings. I wouldn't wear that to work.' (Nancy) 
'I need to kind of think very carefully about, well okay, if I wear, you know, aftershave, you know I can’t make...you can't be too heavy, you know, and how is that going to be perceived by other people?' (Keiran)

As Cunliffe and Coupland (2012: 69) suggest, in the bodily constitution of the self, 'so much of what we do is responsive, intuitive and is interwoven with feelings about ourselves and others'. On one level this was manifest in the extent to which the self-other was conflated in our participants' discussion. We do not know for whom we smell or why we engage in smelling or particular odourising practices - ourselves or someone else. As an active sensorycreating subject, reodourisation enabled bodies to 'blend into each other' through displaying smells that were deemed non-intrusive. In this sense cultural permeability was pervasive, locating norms and values within, around and between bodies, constituting the very experience of being at work in an organisation and demonstrating the power of smell to control certain behaviours whilst enabling others. In one sense, this awareness in itself required a 'switching on' (Hockey, 2009) of sensory apparatus where the body's situated presence in a setting (or world) was reasserted, rather than suppressed. However, in practice, the idea of 'switching' off or on belittles the anxiety surrounding the psychosomatic ability to successfully fulfil socially ascribed expectations of smell. This was of particular concern since no-one would ever tell another of their smell indiscretion:

'When I used to smoke, I didn't used to think I smelled. But then you look (sic) at the clothes that you've been wearing the day before, and oh, horrible, a horrible smell. You think, how can I not smell that on me all the time? And if I can't smell that, can I smell anything, really?' (Harry)

Consequently, engaging with smell and smelling relied on embracing the ambiguity over 
what may be construed as offensive. On the one hand, the importance of 'living' smells that were actively of the body, produced by bodies and experienced between bodies and the spaces they inhabited constituted an important dimension of organisational interaction. In other words, they served as a counterpoint to the disembodied 'dead' smells which accompanied the impersonal physicality of the organisational setting. This was the case even where the 'living' smell was actually an artificial one (but was animated by a person) such as using room fragrance, or wearing perfume. Yet such practices also formed an important role in regulating and subsequently suppressing the distinctly human excretions of bodies, including sweat, breath and wind. This regulation formed part of the work involved in being a professional body, constituting the experience of organisation itself.

\section{Locating smell in-between}

The experience of intercorporeality in and of itself is elusive. This was clear in the participants' accounts of why smell mattered in the workplace:

'In my profession (consultancy) it's... you kind of have to be seen to be (1) good in more than... in lots of aspects ... it's not really tolerated [to] have some like some obvious, like, deficiency is too strong, but some obvious, like, thing, you think, well, you could, in that better you should be doing something sort of different, or you $\underline{\text { shouldn't be coming here with smelly breath (2), or anything. Yes, because people are }}$ paying, sort of quite a lot of money (3), people who come in, so like everything should be [just right]... including the smell (4).' (Henrik)

Similar to other accounts, Henrik's explanation alerts to us the (albeit partial) manifestations of intercorporeality by asserting a particular subject position as an individual responsible for smell (1); a cultural expectation of how one should smell as work (2); the organisational 
(cultural) financial imperative (3), and; noting the materiality of the smell (4). To reduce smell to any of these elements in isolation would fail to capture its lived complexity.

Awareness of these 'smell tapestries' usually emerged when there was a departure from a norm or expectation of smell:

'I'm aware of food smells, but that would probably be about it, I would say. Unless there's anything extremely strong that happens to crop up, but it's just the food that people bring into the office.' (Angela)

'When you're in a print room as well, you smell that paper - you know, papery smell... only when it's something pungent, yes. I mean like something that either smells good or really rotten.' (Rob)

The presentation of a normaitve office smellscape formed an important backdrop in suggesting what were business-as-usual smells compared to other smells that flowed in and out of participants' olfactory schema. However, out-of-place smells were not only defined in terms of their presence or absence, but could also constitute common smells that were viewed as inappropriate in some way. From this emerged particular modes of smell etiquette that were classified in relation to their strength and origin, as well as the place or time when they occurred. For example, many participants talked about colleagues that always smelled of stale sweat, signaling (to them) a lack of personal care. Such accounts illuminated the embodied sociability and therefore the inescapable intercorporeal character of being a working body:

'There's one person in the department who quite often doesn't smell good... she just smells quite a bit of body odour...I just wonder what she doesn't do, so that it has that 
much of an impact. You know, like all it takes is for you to shower every day. But maybe some people have a, you know, they have a stronger smell than others, don't they?' (Olivia)

Olivia's interview extract entwines her physical sensation of smell, and the 'smelly' characteristics of the other person. Other interviews revealed smell as being simultaneously somatically and culturally 'read' in relation to legitimate work-related behaviour: if a smell was directly connected to a legitimate job activity, it may be judged differently and carry less negative connotations. These blurred lines of somatic intentionality afforded the possibility of ascribing meaning in a number of ways. For example, it demonstrated that people were extremely busy, under stress, or had been working long hours:

'It reminds me of, like... it's the men I work with and in, like, things, like, departmental monthly meetings where you're all, like, crammed into a room for about two hours and...yes. And I don't know, for some reason that makes men sweat a little bit I think.' (Holly)

'The odd comment about how somebody smells....usually negative; you know, have you smelt so and so today? They honk. But, you know, you don't know what day they've had. Maybe they’ve had a stressful day, I don't know.' (Harry)

What Holly and Harry highlight is the importance of culture as constituted within these relations, and not a discourse simply laid over them. This experience is more than the sum of separate social performances, cultural expectations and biological processes involved in smelling. In other words, smell is not simply a trigger that lies behind a cultural interpretation but serves to constitute the cultural milieu. As such, smell is constitutive in that it is part of 
the intercorporeal package that suggests 'work is being done here' rather than some other activity. Ambiguity also arises due to the complexity of intercorporeal experience. Sean's account, for example, highlights the ambivalence created through smell encounters where the smell present - including its apprehension as pleasant or unpleasant - cannot be extracted from the reason for its existence:

'A lot of people in my office are quite paranoid about germs, about catching... so we have those like alcohol gels every, like on every desk; and we have like wipes, like sterilising wipes that you can wipe the keyboard with when you get in...that is obviously quite overpowering when someone uses that; a really strong smell...it is a little bit like petrol or nail polish or something that has a slightly - I wouldn't say appealing - but there is something about it which is nice.' (Sean)

However, in practice, there is often a need to negotiate the ambiguity arising from contextually-specific aroma management and to this end, a number of strategies emerged which appeared to be based on a benchmark of unacceptable smells. One example of this was invoking the idea of professional standards, which meant that all individuals should have an implicit understanding of smell etiquette, as highlighted by Olivia:

'You maybe have, like a sort of, not a responsibility, but you know, just not to make things difficult for people around you. Like, I trump [break wind] a lot, but I wouldn't sit and trump at work, you know, I save it for home, because I wouldn't want to put people through that.' (Olivia)

Inherent in these strategies were both shared cultural understandings of professional histories, negotiated via socially-delineated lines of intentionality and an assumption that all bodies can be maintained and controlled in the same way. While this can be partly explained by social taboos surrounding the attribution of bad smells (Synnott, 1991), it also appeared to be 
justified by participants referring to the ephemeral nature of smell. Once it was 'out there' at a material level there was little that could be done about it. However, intercorporeal necessity dictates that we cannot remain passive to this. Relatedly, participants reported a tension between doing something about smells, whilst avoiding direct confrontation:

'I'd tell other people, like, he stinks. No [I wouldn't do anything] unless it was so bad that you couldn't actually work, then you'd have to do something about it, but it would be very difficult. Maybe go to HR or something... [and say] the guy beside me stinks!' (Angela)

'It's quite anti-confrontational, my work. And if people were going to say something, what they would do is they'd send a circular email to everybody, like, talking in theory about should people eat their lunches at their desks, can they not... They're never, like, Marian, your sandwiches stink. It would always be, like, a circular to everybody, just "FYI, can people be aware..." (Holly)

The complex negotiations when 'outing' another person's smell were clearly delineated between specific organisational cultures and the intercorporeal necessities of inhalation. However, all accounts suggested that the act of self-moderating the smells that one causes or excretes was itself framed as a moral imperative. Even though it was acknowledged that the individual may not be aware they were breaking the norms of work smells, smell etiquette also forbids talking directly with the person about their personal smell, despite all participants claiming they would want to be told if they smelled themselves. However, just as Hockey's (2009: 485) infantrymen's 'occupational way of seeing...embraces a visual alertness about one's own body and one's peers', smells were always located as part of a collective workforce experience. In other words, it is the smell, and the practices around it, that make 
up what it means to be 'at work' in an intercorporeal sense. Holly, for example, who worked for a charity, suggests that the smell of the sandwiches (and the subsequent social practices they engendered) were embedded in her diverse workplace which was manifest in both a physical presence in the office of people from a variety of countries and cultures, and a symbol of what the organisation stood for. Cultural inhalation in part constituted the way she experienced work.

\section{Sensual signifiers: openness to the world}

As suggested above, smell as one manifestation of corporeal porosity can be glimpsed through a nexus of individual, cultural, organisational and material elements. Such experiences are never fixed due to the relations between bodies and things, and our reliance on these interrelations to both constitute and make sense of the world. To some extent, 'nose talk' was more powerful for our participants than other sensory devices for communication of feeling, revealing a form of visceral knowing. For example, here in the act of drinking coffee, the smell of coffee also connected to other dimensions of work:

'Day two, 5:13pm(1). I'm just back from a fairly important meeting; I've been working on this for seven to ten days (1). There are some... I can smell the scent of coffee (2). When people normally get that it usually means that we are in for a long

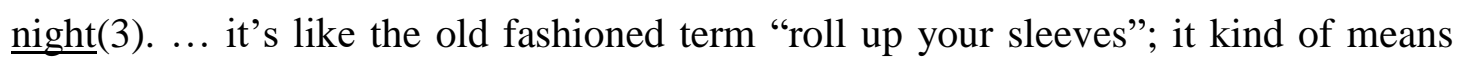
the same now.' (Henrik, Diary recording)

The separation of the smell of coffee from the source of coffee itself (2), results in the aroma taking on the mode of a sensual signifier (3). Similar to a material signifier, the substance of the smell (i.e. the odour particles) may have a level of constancy (e.g. most people would recognise the smell as coffee no matter where it was encountered), but its meaning is not 
fixed because it relies on the socio-historical context and cultural interpretations, in this case the time of day $-5: 13 \mathrm{pm}-$ and the relationship to an important project (1). What makes the smell of coffee a sensual signifier (rather than remaining a material one) is its common perception as separate from 'coffee' as a tangible object, whether as beans, ground powder or a hot drink. This is rooted in our participants' experiences of smell where they distinguished between smells and the objects that they emanated from, echoing Ingold's (2011) observation that it is at the surfaces of things that we understand the changing character of matter. However, unlike material signifiers, where a physical object may trick us into considering some stability, the lack of material fixity of sensual signifiers means that our relationship with the smell opens up an imagined space that is both socially shared, experientially gained, and mutable.

Situated presence was vital here, suggesting that a series of habituated intercorporeal embodied practices contributes to the routinisation of office life. Each participant's experience of their workplace was made up of a smell tapestry that included the smell of office equipment, people, air circulation patterns (such as windows or air conditioning) and, more significantly, the interaction between these different elements. However, since the experience of these elements was contingent on the presence and movements of different bodies, they were not repetitive routines, but rather recursive, always slightly shifting views on smell in the immediacy of the smelling act. Sensual signifiers are thus essential to the rearrangement and renewal of 'corporeal exchanges' (Weiss, 1999: 2) that take place within and between bodies and the negotiation on what goes in and out of our bodies. This manifested in the orientation of participants in relation to smell, and therefore to the wider social schema. One example of this was locating temporally or spatially orientated experiences: 
'Monday 12:30. I'm sat at my desk and I can smell a lovely smell. It's food. I think somebody's heated up a stew in the microwave. It must be lunchtime. Feeling hungry now.' (Elaine: Diary recording)

[about men's toilets smelling] 'At certain times of the day, like, like, sort of, mid to late morning and after lunch. Some people are really regular as well because I know when they're going to come upstairs.' (Olivia)

'Quite often the girls, when they leave, will put deodorant or perfume on and then... especially on a Friday if they're going out. "Oh, it smells a bit nice in here”, you know. Because they're obviously going out somewhere.' (Megan)

Various aromas and the act of smelling them created a web of connections where the habits and behaviours of others, even if undertaken in isolation, collapsed into the experience of those around them, constituting the embodied sociality of the workplace. In this respect, the porosity across and between bodies highlights, inter alia, how ritualised activity helps construct group cohesion and community, in a similar way to Flores-Pereira et al.'s (2008) after work drinking rituals. But in our data, it also appeared that sensual signifiers were particularly powerful in doing so within the workplace as they enabled interaction to transcend relations mapped out according to job role, as well as constituting relations beyond work-related teams. For example, many participants recalled talking about food smells to colleagues as a form of social lubricant to ease over working relationships, as explained by Sean: if it is something really nice, people might go "oh, my god, that smells so good", you know, "what is it"; "try and find out".' As Driver (2008: 930) suggests, 'food practices have meaning as well as materiality'. Even though many of our participant's examples were not 
directly 'work smells' in terms of being connected to formal tasks and practices, their affinity with other desirable spaces or locations was integral to how they experienced work. This is reminiscent of Flores-Pereira et al.'s (2008: 1020) participants, who drew on different cultural scripts to 'misbehave' - bodily practices that although appeared to be experienced as 'spontaneous, they did not overstep a specific repertoire of physical arrangements'. Similarly, for our participants, whether smelling could be attached to different but nonetheless legitimate settings or behaviours meant that at times smell may not completely transgress but instead only appear as 'a little out of place'.

However, to acknowledge the circular relation between smell as both signifier and material constituent relies on an intercorporeal ontology which occurs as a 'mode of presence and engagement' (Csordas, 1993: 135) - in other words, expression that is never locatable at the level of one individual, experience or object. This is suggested in Keiran's account of a colleague complimenting his room spray:

'It put me in quite a good mood because I thought; it was almost... she was vindicating my choice of fragrance for the room and actually I felt vindicated that it was a good choice, that actually it was pleasant to other people, not just me'.

For Keiran, as with other participants, the ontology of smelling relies on the active constitution of a corporeal porous agent with a 'certain manner of managing the domain of space and time... in short a certain manner of being, in the active sense' (Merleau-Ponty, 1968: 115). Our participants formed, rehearsed and repeated social ties through these relations, embedded in the affective ties created in perfumes, lunches or other aromas.

\section{Discussion}


To both know the world and be in it requires practical embodied involvement - to smell, to not smell, or to react to a smell. While this often occurs at a pre-reflective level, it is bound up with cultural, historical and experiential understandings to the extent that we are constantly engaged in a mode of 'socially instinctive automatism' (Flores-Pereira et al., 2008: 1023). On the one hand this shapes how bodies are at work which intertwines with organisational requirements and professional objectives; as Cunliffe and Eriksen (2011: 1442) suggest, we can be viewed as "creatures" feeling their way around interactions with others, figuring what to say, how to act and how to get things done: sometimes seemingly intuitively, other times more deliberate' (Cunliffe and Eriksen, 2011: 1442). As our data has shown, the 'deliberate' end of the spectrum involves a great deal of labour in itself to negotiate the embodied demands of smelling, or not smelling, and in practices, such as refereeing smelly people and their residues. However, such negotiation is both an ontological and epistemological imperative. While bodily integrity has been aligned with significant bodily events such as transplants to show the 'insistent potential of radically different modes of embodiment' (Shildrick, 2010: 11-12), the term also provides us with a theoretical language to articulate a bodily process that physically enters the working body. By necessity we are always situated within and between relations as a means of knowing, being and acting. The body though necessity must enact organising regimes since it is constituted through the 'open-ended human process of taking up and inhabiting the cultural world, in which our existence transcends but remains grounded in de facto situations' (Csordas, 1990: 10 italics added). We would agree with Tomkins and Eatough (2013: 266) that the body sends us 'clues about the meanings and multiplicities of our engagement in the world'. To this we would add that bodily integrity also means that we simultaneously 'push' these clues back into the world through the coordination, interdependence and synthesis of sensual bodies. 
The seeping of smell into and from our bodies forms one manifestation of corporeal porosity in day to day office interactions experienced as part of the incumbent need for bodily integrity. This potentially reimagines different facets of organisational life as configured through our permeable corporeal experience. We have therefore extended the growing literature on organisational intercorporeality in an explicitly sensory - and here olfactory direction to highlight how permeability is involved in a corporeal seeping and secretion and is not simply discursive or theoretically abstract. Just as Hindmarsh and Pilnick's (2007) anesthetists picked up on the actions of other bodies in the conduct of their tasks, and were affected by the presence of others, our participants smell practices were always situated within a consideration of the co-proximity of other bodies, cultural contexts and the materiality of the workplace. Moreover, exploring these dimensions empirically addresses the 'sensory lacuna' (Hockey, 2009: 478) that has hitherto been the case in accounts of office work. Our findings suggest that workplaces - and especially office environments - are not blank smellscapes but heady concoctions of bio-socially produced and understood perfumes, aromas, scents and stinks that form a specific organised smellscape integral to the experience of 'being at work'.

Smell, as one element of an intercorporeal life that refuses to manifest into a sensible visibility, shows the entanglement of bodies in the production of selfhood, the constitution of how it feels to be a working body, and how we cohere ourselves and others in the course of work in organizations. In a sense, smells are physical indexes of what they also symbolise to people. They are detached and free-floating particles of their source (Waskul and Vannini, 2008), sensual signifiers of the enacted routines peculiar to particular settings. As Martin's study of care home workers and residents (2002: 867) suggests, sensual signifiers can result in an enacted 'conception of bodies - as strong or weak, able or disabled, touchable or 
untouchable, clean or dirty, fair or foul smelling - in ways that [shape] residents' perceptions, experiences, and feelings.' However, attention to smell also provides a route to a fuller, more sensual human explanation of the micro-processes that buzz between us as bodies who organise, highlighting the ongoing necessity of bodily integrity as we assert our coherence as a body-amongst-other-bodies. The context of work is important here, with smell revealing the facticity of the bodily blend between personal and social. To this extent, 'individual and collective narratives are implicate[d]' in creating organisational realities (Cunliffe and Coupland, 2012: 68). For example, smells as signifying the time of day (say, 12 noon) and hunger were indistinguishably experienced, which elicited a culturally articulated resolve (lunch).

Verbeek and van Campen (2013: 138) suggest that 'every (sub)culture has its own collective olfactory memory' and the lingering expectation by participants that professional work does not smell suggested that, unlike Hockey's (2009) infantrymen who 'switched on', office work initially assumed the need to sensually 'switch off' in order to perform at work. In one sense this can be read as a sensual manifestation of Weber's impersonalised bureaucracy operating 'without regard for person' (Weber, 1968: 975) or more recently the fluidity, transience and the 'until further notice' orientation which is characteristic of contemporary capitalism (Bauman, 1998). A workplace that does not smell is bland and empty in a similar vein to the depersonalised, open-plan and clear-desk office environments that characterise many people's workplace experiences (see Warren 2006). You cannot get too attached to it, or to anything in it. You can make no mark on it, it makes no mark on you and it is not 'yours'. However, on further exploration, drawing on sensual methodologies helps us to glimpse the numerous olfactory orders at play that both affirm and transgress norms of smell etiquette and expectations. These accounts can tell us much about how social fabrics of the 
workplace are constructed and maintained within the conditions of embodied subjectivity. Similar to Haynes' (2008: 339) study of female accountants' experience of pregnancy, for our participants, at the intersection of organisation and smell 'the body impacts more directly on abilities [...] to cope with all the expectations leveled at them'. Smell resulted in individuals having to negotiate the line between professional conduct as inscribed by discourses and organisational practices, and their lived embodied experience of feelings and desires surrounding hunger, bodily functions, breathing in other bodies, immediate reactions to strong or overpowering aromas, and disgust in not liking particular smells. To accept a fully human working body - senses, smells and all - is to accept the unbounded, messy, unpredictability of employees, foregrounding the constantly active and intercorporeal character of embodied organisational lives.

\section{Conclusion}

We accept that to write about corporeal porosity is to ultimately limit it to a textual reduction that only offers a glimpse of the embodied processes at play, echoing broader methodological debates surrounding the politics of representation when researching sensual life (c.f. Mason and Davies, 2009). However, acknowledging the importance of smell as an intercorporeal phenomenon gets to the heart of many fundamental quandaries that challenge our view of organisational life and organisational beings as somehow ontologically distinct or separable from each other, prima facie. Understanding one phenomenon - smell - helps to consider the moving, dynamic, lived experience of work as not only intersubjective but about negotiating the material and ontological boundaries of our existence. The inherent and inevitable reciprocity of feelings and actions are always inhaled through, within and across bodies and subsequently craft work experience. It also provides a conceptual and empirical way of breaking through the assumption of the disembodied worker and acknowledging the 
intercorporeal creativity involved in negotiating working life. What we have unpacked here at least gives some form to the fleeting experiences of diffuse, taken-for-granted senses of rightness, understanding and smooth functioning in workplace life. To bring it to matter, we acknowledge how the spontaneity that partly forms bodily integrity in our day to day experience of work involves the entanglement of biology, history, environment, emotion, memory and social order - all in a sniff.

\section{References}

Abram D (1996) The Spell of the Sensuous. New York: Vintage Books.

Bauman Z (1998) Work, Consumerism and the New Poor. Oxford: Blackwell.

Classen C (1997) Foundations for an anthropology of the senses. International Social Science Journal 49(153): 401-412.

Classen C, Howes D and Synnott A (1994) Aroma: A Cultural History of Smell. London: Routledge.

Corbett JM (2006) Scents of identity: Organisation studies and the cultural conundrum of the nose. Culture and Organization 12(3): 221-232.

Corbin A (1986) The Foul and the Fragrant: Odor and the French Social Imagination. Cambridge MAS: Harvard University Press.

Crossley N (1996) Body-subject/body-power: agency, inscription and control in Foucault and Merleau-Ponty. Body and Society 2: 99-116.

Csordas T (1990) Embodiment as a paradigm for anthropology. Ethos 18(1): 5-47.

Csordas T (1993) Somatic modes of attention. Cultural Anthropology 8(2):135-156.

Csordas T (1999) Embodiment and cultural phenomenology. In: Weiss G and Haber H (eds) Perspectives on Embodiment. New York: Routledge, 143-162.

Csordas T (2008) Intersubjectivity and intercorporeality. Subjectivity 22 (1): 110-121. 
Curtis B (2008) I can tell by the way you smell: dietetics, smell, social theory. Senses and Society 3(1): 5-22.

Cunliffe A and Coupland C (2012) From hero to villain to hero: making experience sensible through embodied narrative sensemaking. Human Relations 65(1): 63-88.

Cunliffe A and Eriksen M (2011) Relational leadership. Human Relations 64(11): 1425-1449.

Dale, K. (2001) Anatomising Embodiment and Organisation Theory. Hampshire: Palgrave.

Davies BJ, Kooijman D and Ward P (2003) The sweet smell of success: olfaction in retailing. Journal of Marketing Management 19(5-6): 611-627.

Driver M (2008) Every bite you take... food and the struggles of embodied subjectivity in organizations. Human Relations 61(7): 913-934.

Drobnick J (2006) Introduction: olfactocentrism. In: Drobnick J (ed) The Smell Culture Reader. Oxford: Berg, 1-12.

Fine G (1996) Kitchens: The Culture of Restaurant Work. Berkeley: University of California Press.

Flores-Pereira MT, Davel E and Cavedon NR (2008) Drinking beer and understanding organizational culture embodiment. Human Relations 61(7): 1007-1026.

Gabor E (2013) 'Tuning' the body of the classical musician: an embodied approach to vocational anticipatory socialization. Qualitative Research in Organizations and Management: An International Journal 8(3): 1-22.

Gell A (1977) Magic, perfume, dream... In: Lewis I (ed.) Symbols and Sentiments: CrossCultural Studies in Symbolism. London: Academic Press, 25-37.

Haynes K (2008) (Re) figuring accounting and maternal bodies: the gendered embodiment of accounting professionals. Accounting, Organizations and Society 33(4): 328-348.

Herz RS (2003) The effect of verbal context on olfactory perception. Journal of Experimental Psychology: General 132(4): 595-606 
Hindmarsh J and Pilnick A (2007) Knowing bodies at work: embodiment and ephemeral teamwork in anaesthesia. Organization Studies 28(9): 1395-1416.

Hockey J (2009) 'Switch on': sensory work in the infantry. Work Employment and Society 23(3): 477-493.

Hockey J and Allen-Collinson J (2009) The sensorium at work: the sensory phenomenology of the working body. Sociological Review 57(2): 217-39.

Holt R and Sandberg J (2011) Phenomenology and organization theory. Research in the Sociology of Organizations 32: 215-249.

Howes D (2010) Sensual Relations: Engaging the Senses in Culture and Social Theory. Ann Arbor: University of Michigan Press.

Ingold T (2011) Being Alive: Essays on Movement, Knowledge and Description. London: Routledge.

Jervis L (2001) The pollution of incontinence and the dirty work of caregiving in a US nursing home. Medical Anthropology Quarterly 15(1): 84-99.

Kavanagh D (2004) Ocularcentrism and its others: a framework for metatheoretical analysis. Organization Studies 25(3): 445-464.

Lindstrom M (2010) Brand Sense: Sensory Secrets Behind the Stuff we Buy. London: Kogan. Low K (2005) Ruminations on smell as a sociocultural phenomenon. Current Sociology 53(3): 397-417.

Lyon D and Back L (2012) Fish and fishmongers in a global city: socio-economy, craft, and social relations on a London market. Sociological Research Online 17(2): http://www.socresonline.org.uk/17/2/23.html.

Martin P (2002) Sensations, bodies, and the 'Spirit of a place': aesthetics in residential organizations for the elderly. Human Relations 55(7): 861-885. 
Mason J and Davies K (2009) Coming to our senses? A critical approach to sensory methodology. Qualitative Research 9(5): 587-603.

Merleau-Ponty M (1968) The Visible and the Invisible. Trans. Lingis A. Evanston: Northwestern University Press.

Morrin M (2010) Scent marketing: An overview. In: Krishna A (ed.) Sensory Marketing: Research on the Sensuality of Products. London: Routledge, 75-86.

Ong W (1969) World as view and world as event. American Anthropologist 71(4): 634-647. Palmer R (1993) In bad odour: smell and its significance in Medicine from antiquity to the seventeenth century. In: Bynum WF and Porter R (eds) Medicine and the Five Senses. Cambridge: Cambridge University Press, 61-68.

Pink S (2009) Doing Sensory Ethnography. London: Sage.

Porteous JD (1985) Smellscape. Progress in Physical Geography 9(3): 356-378.

Radcliffe-Brown AR (1946) The Andaman Islanders. New York: The Free Press.

Rasmussen S (1999) Making better "scents" in anthropology: Aroma in Tuareg sociocultural systems and the shaping of ethnography. Anthropological Quarterly 72(2): 55-73.

Seigworth G and Gregg M (2010) An inventory of shimmers. In: Gregg M and Seigworth G (eds) The Affect Theory Reader. Durham and London: Duke University Press, 1-25.

Senses and Society (2006) Introducing sensory studies. Senses and Society 1(1): 5-7.

Shepherd GM (2005) Outline of a theory of olfactory processing and its relevance to humans. Chemical Senses 30(suppl 1): i3-i5.

Shepherd J (2010) School tests peppermint aroma to help students concentrate. The Guardian $U K, 23^{\text {rd }}$ April.

Shildrick M (2010) Some reflections on the socio-cultural and bioscientific limits of bodily integrity. Body \& Society 16(3): 11-22. 
Shilling C (1993) The Body and Social Theory. London: Sage.

Synnott A (1991) A sociology of smell. The Canadian Review of Sociology and Anthropology 28: 437-459.

Tomkins L and Eatough V (2013) The feel of experience: phenomenological ideas for organizational research. Qualitative Research in Organizations and Management: An International Journal 8(3): 258-275.

Verbeek C and van Campen C (2013) Inhaling memories: smell and taste memories in art, science, and practice. The Senses and Society 8(2): 133-148.

Wade NJ (2009) The search for the sixth sense: the cases for vestibular, muscle and temperature senses. In: Howes D (ed.) The Sixth Sense Reader. Oxford: Berg, 55-86.

Warren S (2006) Hot Nesting? A visual exploration of personalised workspaces in a 'hotdesk' office environment. In: P Case, S Lilley and T Owens (eds.) The Speed of Organization. Copenhagen: Copenhagen Business School Press, 119-146

Warren S and Riach K (2014) Developing an olfactory methodology for researching workplace smell: A research note. Essex Business School Working Paper Series 2014/04. available at http://www.essex.ac.uk/ebs/research/working_papers/.

Waskul D and Vannini P (2008) Smell, odor, and somatic work: sense making and sensory management. Social Psychology Quarterly 71(1): 53-71.

Waskul D, Vannini P and Wilson J (2009) The aroma of recollection: olfaction, nostalgia, and the shaping of the sensuous self. The Senses and Society 4(1): 5-22.

Weber M (1968) Economy and Society. Roth G and Wittich C (ed.). New York: Bedminister Press.

Weiss G (1999) Body Images: Embodiment as Intercorporeality. London: Routledge.

Williams E (2000) 'Satanic mills' see the light. The Independent, $3^{\text {rd }}$ September.

Wolkowitz C (2006) Bodies at Work. London: Sage. 